\title{
Detonadores de la modernización tecnológica en la industria gráfica de México: una metodología y un caso de éxito
}

\section{Detonators of Technological Modernization in the Printing Industry of Mexico: a Methodology and Case Study}

\author{
Munive-Rojas Miguel Ángel \\ Facultad de Ciencias Básicas, Ingeniería y Tecnología \\ Universidad Autónoma de Tlaxcala \\ Correo:mmunive@ingenieria.uatx.mx
}

Información del artículo: recibido: julio de 2013, reevaluado: marzo de 2014, aceptado: agosto de 2014

\begin{abstract}
Resumen
El arte gráfico comprende a todas aquellas actividades relacionadas con la preparación, producción y terminado de obras impresas en diferentes tipos de sustratos. De acuerdo con la Cámara de la Industria de las Artes Gráficas y de la Unión de Industriales Litógrafos de México, este sector requiere asumir gran impulso estratégico en materia de modernización que le consolide en la economía nacional y al mismo tiempo le conduzca hacia mercados internacionales. Sobre una base de cuarenta casos de éxito este trabajo de investigación utiliza el método cualitativo y de entrevistas abiertas para indagar sobre los detonadores más importantes que conducen a la industria de la impresión en México hacia la modernización tecnológica, en una segunda etapa se utiliza el enfoque cuantitativo y de evaluación sumaria tipo Likert para medir el impacto de estos factores. Con base en el análisis de estos casos de éxito y de la determinación de estos detonadores se propone una metodología de modernización tecnológica que le servirá estratégicamente a estas empresas para orientarlas hacia la modernización de sus procesos. Finalmente se presenta un caso de éxito en una empresa litográfica donde la metodología se puso en marcha y dio como resultado el mejoramiento de su productividad y de la modernización de sus procesos sin una gran inversión.
\end{abstract}

\section{Descriptores:}

- artes gráficas

- productividad

- modernización tecnológica

- estrategia e innovación 


\begin{abstract}
The graphic art includes all activities related to the preparation, production and finishing of printed works on different types of substrates. According to the Chamber of Industry of Graphic Arts and the Union of Industrial Lithographers of Mexico, this sector needs to implement strategies for modernization that will strengthen the national economy and at the same time will lead to international markets. On a base of forty case studies this research uses a qualitative method and open interviews to investigate the most important triggers that lead to the printing industry in Mexico toward technological modernization. In a second stage, a quantitative approach and Likert summative evaluation were used to measure the impact of these factors. Based on the analysis of these case studies and the determination of these detonators, a methodology for technological modernization was proposed, which will serve to guide these companies strategically towards modernizing its processes. Finally, a case study is presented in a lithographic company where the methodology was implemented and resulted in improving their productivity and modernizing their processes without a big investment.
\end{abstract}

\section{Introducción}

De acuerdo con Reyes (2010) en los últimos 25 años el cambio más sorprendente en la arquitectura de negocios es el de la rapidez, el de la diversidad y el del impacto del cambio; por lo que se puede asegurar que el cambio "cambió". Hoy en día la importancia de una visión integral que contemple las circunstancias, el contexto y los pronósticos tanto de los mercados y de las tecnologías son fundamentales para la industria gráfica del futuro. Actualmente Estados Unidos, Japón y China, países que lideran el ramo gráfico, están migrando hacia estructuras integrales y digitalizadas de alto contenido tecnológico que intentan automatizar todos los aspectos administrativos y productivos del negocio, además de que las economías más desarrolladas están buscando el mercado de especialidades y de soluciones gráficas, al mismo tiempo que transfieren sus tecnologías y productos convencionales hacia las economías emergentes. Por otra parte, las estrategias de negocios a nivel mundial han pasado de establecer el foco en la oportunidad (just in case) para adoptar un enfoque en la eficiencia (just in time) y recientemente en el atributo (just for you). Estas dos últimas estrategias de negocios obligan a la planta gráfica en México a mantener un nuevo enfoque basado en la simplificación de las operaciones (lean enterprise) y en la diversificación de la mezcla de especialidades de producción en tiros cortos. Es en este sentido que las competencias medulares de la industria de las artes gráficas en México deben basarse en las capacidades de la organización para darse cuenta, dar sentido y hacerse cargo. De acuerdo con lo anterior, la industria de la impresión en México busca los mecanismos para la modernización tecnológica que le permitan la flexibilización de sus procesos, el incremento de sus corridas de producción, la reducción de sus desperdicios, la mejora social y del medio ambiente. En aras de la penetración cada vez más intensa de los sistemas digitales, las empresas gráficas de México deberán orientar y preparar sus procesos para basarlos en una manufactura integrada por computadora con el fin de acceder a las tecnologías de impresión digitalizadas.

\section{La industria de las artes gráficas en el mundo}

Según el Glosario General de Artes Gráficas (2010), se entiende por arte gráfico a las profesiones, empresas y ocupaciones industriales relacionadas con la creación de productos impresos. Diseño gráfico, pre impresión, impresión, encuadernación y ocupaciones similares están directamente relacionadas con las artes gráficas. De acuerdo con la Unión Industrial Argentina (UIA, 2011) los principales sistemas de impresión son los los que se muestran en la tabla 1. De acuerdo a PRIMIR 'Word Wide Market for Print' (2009) los mercados que lideran el ramo de la impresión son los mostrados en la tabla 2.

Para Payne (2007) y Terni (2008) el mercado mundial de la impresión se caracteriza por un rompimiento de la demanda de impresión en regiones desarrolladas, una fragmentación de las sociedades, un incremento súbito de la globalización, el internet como principal competidor de la impresión, el rompimiento del GDP (Gross Domestic Product) en países desarrollados, además de la presión para mejora social y del medio ambiente. Aún así, las perspectivas del mercado de la impresión para Payne son buenas porque sobre una base global de comercio este sector de la economía prosperará. Norteamérica se mantendrá como el mer- 
Tabla 1. Principales sistemas de impresión y productos

\begin{tabular}{|c|c|c|}
\hline Impresión & Características & Principales productos \\
\hline Offset & $\begin{array}{l}\text { Impresión indirecta base agua-tinta con herramental } \\
\text { plano }\end{array}$ & Forma continua, papelería, etiquetas, revistas y libros \\
\hline Flexografía & Impresión directa base tinta y plancha de goma & $\begin{array}{l}\text { Autoadhesivos, corrugados, empaques y envases } \\
\text { flexibles }\end{array}$ \\
\hline Huecograbado & Impresión directa base tinta y herramental al bajo relieve & Etiquetas y envases flexible \\
\hline Serigrafía & Impresión directa base tinta y pantalla de nylon & Impresos de seguridad y de valores \\
\hline Digital & $\begin{array}{l}\text { Impresión directa basada en principios xerográficos y } \\
\text { laser }\end{array}$ & Trabajos sobre pedido \\
\hline
\end{tabular}

Fuente: Unión Industrial Argentina (2011)

Tabla 2. Ranking internacional de la impresión

\begin{tabular}{cccccc}
\hline Lugar & País & $\begin{array}{c}\text { Ventas 2006 en } \\
\text { millones de dólares }\end{array}$ & $\begin{array}{c}\text { Crecimiento 2005- } \\
\text { 2006 }(\%)\end{array}$ & $\begin{array}{c}\text { Ventas 2011 en } \\
\text { millones de dólares }\end{array}$ & $\begin{array}{c}\text { Crecimiento } \\
\text { 2006-2011 }(\%)\end{array}$ \\
\hline $1^{\circ}$ & EUA & 182000.7 & 2.8 & 196722.7 & 8.1 \\
$2^{\circ}$ & Japón & 84976.0 & -3.3 & 88363.7 & 4.0 \\
$3^{\circ}$ & China & 41200.0 & 17.0 & 65934.1 & 60.0 \\
$10^{\circ}$ & Brasil & 12552.2 & 18.5 & 19192.2 & 52.9 \\
$11^{\circ}$ & México & 12277.5 & 7.1 & 16550.4 & 34.8 \\
$12^{\circ}$ & India & 12131.0 & 7.8 & 20990.7 & 73.0 \\
\hline
\end{tabular}

Fuente: PRIMIR (2009)

cado más grande de la impresión, el énfasis deberá colocarse en el cambio del mundo desarrollado al mundo emergente, los productos que declinen en el mercado desarrollado serán bien recibidos por los países emergentes, los manufactureros necesitan ver a los mercados con grandes poblaciones y con rápidos radios de crecimiento.

\section{La industria gráfica de México}

La división VII de la economía en México denominada como "papel, impresión e industrias relacionadas" está constituida por dos grandes ramas:

a) La primera denominada papel y productos de papel (abarca a las empresas de celulosa y papel, que son medianas y grandes e intensivas en capital).

b) La segunda denominada imprenta y editoriales (incluye predominantemente micro y pequeñas empresas).

En la siguiente figura 1 puede advertirse un panorama amplio de la caracterización de la división VII.

En el caso de la micro y pequeña empresa, se pueden identificar diferencias por tamaño y por región; en una encuesta realizada para la Cámara Nacional de la Industria de las Artes Gráficas, se observó que estas enfrentan severas dificultades. Así lo muestra el nivel de utilización de su capacidad, ya que apenas 35\% trabaja- ba a más de $60 \%$ de su capacidad instalada y, en lo relativo a los turnos trabajados, solamente $11 \%$ labora dos turnos. Se compara desfavorablemente con la encuesta realizada por la Unión de Industriales Litógrafos de México, relativa a las industrias medianas y grandes, de las cuales $65 \%$ utiliza $60 \%$ o más de su capacidad instalada y $53 \%$ trabaja dos turnos o más. De acuerdo con la CANAGRAF (2010) la industria gráfica se concentra en los siguientes centros demográficos: DF, Edo. de México, Nuevo León, Jalisco, Tamaulipas y Veracruz. Las empresas de esta rama tiene solo 3\% de la inversión extranjera y el capital de los Estados Unidos representa $60 \%$ del total de recursos foráneos que reciben las empresas de imprentas, editoriales e industrias conexas. Las empresas dedicadas a este giro escasamente registran procesos de aseguramiento de calidad. Los problemas que sufren las empresa gráficas mexicanas son la falta de planeación y programación, la escasez de recursos financieros, lo que impide la modernización, defectos de calidad y la falta de recursos humanos capacitados. Las empresas consideran como principales aspectos a mejorar la renovación de la maquinaria y la modernización de los procesos de producción. La competencia externa de esta industria proviene de los Estados Unidos de Norte América. Además de estos aspectos se advierten nuevas y crecientes exigencias entre las que se consideran: la introducción de la Internet, la exigencia de nuevas normas de calidad, una 


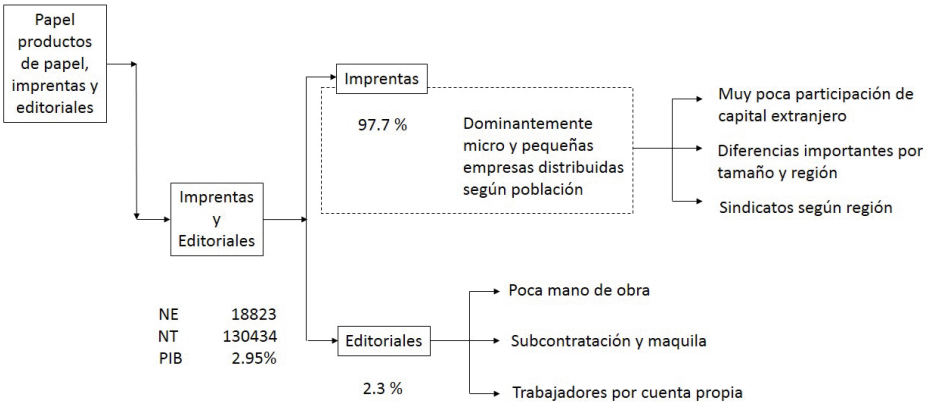

Figura 1. Caracterización de la división VII. Elaboración propia con información de EAIM-INEGI (2012) competencia globalizadora, innovación tecnológica en procesos de producción, nuevas formas de organización. Para Expo Gráfica y la Asociación Nacional de Industriales y Distribuidores para la Industria Gráfica (2009) la innovación y el desarrollo tecnológico son los elementos fundamentales que influyen en el escenario de la competitividad del mundo gráfico. En este sector confluyen tres factores vitales para que las empresas mexicanas sean competitivas: contar con procesos y equipo de calidad, precios accesibles y servicio postventa. En resumen y de acuerdo con analistas e instituciones afines a este sector la industria gráfica de los países emergentes presentan las siguientes áreas de mejoramiento: renovación tecnológica de productos y procesos, creación de nuevos modelos de negocios, capacitación y organización para las tecnologías digitales, flexibilización de materiales y procesos, mejoramiento de la productividad, estrategias de innovación tecnológica, mejores mecanismos de financiamiento y acceso a mercados globalizados. Es en este sentido como la industria gráfica tiende a buscar similarmente nuevas tecnologías, irrumpir en mercados globalizados, elementos de organización y modernización e innovación empresarial, así como el mejoramiento de la productividad y la flexibilización de los procesos para atender a un mercado cambiante y fragmentado.

\section{La modernización empresarial y tecnológica}

De acuerdo con Dombois y Pries (1993) se entiende por modernización industrial o empresarial a todos aquellos cambios organizacionales conjuntamente con el cambio tecnológico en los procesos de producción. Según los autores se trata de una evolución sistémica que nace en Japón a mediados de los años 50's y que se difunde con múltiples variantes en todo el mundo. Estas nuevas tecnologías facilitan la producción de bienes y servicios diferenciados e incrementan la productividad y por lo tanto potencian la valorización del capital. Según Gamboa (2003) para llevar a cabo la mo- dernización empresarial las empresas ejecutan estrategias empresariales que son entendidas como: los medios para lograr los cambios a mediano y largo plazo con el propósito de obtener ventajas comparativas $\mathrm{u}$ oponerse a las actuaciones presentes o futuras de los competidores. A ellas subyacen principios, valores y fines que determinan la dirección de las empresas; además la estrategia persigue un conjunto de esfuerzos para integrar y coordinar en un todo coherente, recursos y operaciones en función de alcanzar objetivos o fines generales. Para Arellano (2004) una síntesis de las estrategias de modernización empresarial son las que se muestran en la tabla 3.

Para Laffitte (2001) se entiende por modernización tecnológica a la mejora o modificación de los productos o procesos que se están utilizando por una empresa; tal es el caso de la construcción de plantas piloto, el desarrollo y la producción de prototipos, las precorridas de producto, la introducción de equipo que eleve el nivel tecnológico de la planta, la introducción de una tecnología para la gestión de la producción y la calidad que potencien la productividad, además de todas aquellas actividades en la transición de la etapa piloto a la etapa industrial. Para Gamboa (2003) actualmente las empresas hacen uso de la modernización tecnológica en la producción para coordinar actividades dispersas, incrementar la flexibilización, acceder a mercados globalizados, alterar diseño de producción y controlar efectivamente al personal de planta. En su artículo "Eight Business Technology Trends to Watch" Manyika, Roberts y Sprague explican cómo ocho tendencias tecnológicas están cambiando la manera de hacer negocios, entre ellas la expansión de las fronteras de la automatización. Además Porter y Millar (2001) aseguran que las empresas están inmersas en una revolución tecnológica como consecuencia del avance de la tecnología, de aquí que la planta industrial debe hacer uso de estas herramientas para tener el control de la actividad empresarial, o bien, estas empresas serán forzadas a utilizar estas herramientas 
Tabla 3. Estrategias intraempresa

\begin{tabular}{|c|c|c|}
\hline Tipo & Estrategia especifica & Fines \\
\hline $\begin{array}{l}\text { Modernización de } \\
\text { procesos }\end{array}$ & $\begin{array}{l}\text { Modernización informática } \\
\text { Modernización tecnológica en } \\
\text { producción } \\
\text { Reestructuración organizativa }\end{array}$ & $\begin{array}{l}\text { Adquirir mayor capacidad para responder a } \\
\text { fluctuaciones del mercado } \\
\text { Reducir costos a mediano y largo plazo } \\
\text { Optimizar procesos }\end{array}$ \\
\hline $\begin{array}{l}\text { Relacionadas } \\
\text { con la fuerza de } \\
\text { trabajo }\end{array}$ & $\begin{array}{l}\text { Flexibilización del contrato de } \\
\text { trabajo } \\
\text { Socialización laboral }\end{array}$ & $\begin{array}{l}\text { Reducir costos } \\
\text { Desarrollar identidad corporativa } \\
\text { Control ideológico de la fuerza de trabajo }\end{array}$ \\
\hline $\begin{array}{l}\text { Relativas al } \\
\text { producto }\end{array}$ & $\begin{array}{l}\text { Desarrollo de productos } \\
\text { Diversificación productiva } \\
\text { Concentración productiva }\end{array}$ & $\begin{array}{l}\text { Evitar la saturación del mercado } \\
\text { Acelerar el desgaste del producto } \\
\text { Evitar la dependencia de un solo negocio } \\
\text { Ampliar el mercado } \\
\text { Reducir costos }\end{array}$ \\
\hline
\end{tabular}

Fuente: Arellano (2004)

Tabla 4. Estrategias de modernización tecnológica

\begin{tabular}{|c|c|c|}
\hline Cambios estratégicos recientes & Sustitución de Importaciones & Globalización económica \\
\hline Cambio del modelo económico & $\begin{array}{l}\text { Apoyo estatal. Mercados e industria } \\
\text { protegidos }\end{array}$ & $\begin{array}{l}\text { Apertura comercial y financiera. Inversión } \\
\text { extranjera. Exposición a la competencia }\end{array}$ \\
\hline $\begin{array}{l}\text { Cambios en la propiedad de las } \\
\text { empresas }\end{array}$ & Concentración nacional. Grupos familiares & Alianzas estratégicas con capital internacional \\
\hline Cambios en los sistemas productivos & $\begin{array}{l}\text { Búsqueda de la optimización. Sistemas } \\
\text { rígidos. }\end{array}$ & Introducción de sistemas flexibles \\
\hline $\begin{array}{l}\text { Cambios en los sistemas de } \\
\text { distribución }\end{array}$ & Comercialización de la producción propia & Comercialización de productos extranjeros \\
\hline Consultorías & $\begin{array}{l}\text { Contratación de consultores externos, } \\
\text { principalmente nacionales }\end{array}$ & $\begin{array}{l}\text { Contratación de consultores externos, tanto } \\
\text { nacionales como internacionales }\end{array}$ \\
\hline $\begin{array}{l}\text { Desarrollo de nuevos negocios, } \\
\text { pequeños y medianos }\end{array}$ & Desarrollo de negocios propios, nacionales & $\begin{array}{l}\text { Desarrollo de franquicias, principalmente de origen } \\
\text { estadunidense }\end{array}$ \\
\hline Productividad y calidad & Medición incipiente de la productividad & $\begin{array}{l}\text { Introducción de sistemas de medición de la } \\
\text { productividad y acreditación de la calidad }\end{array}$ \\
\hline Sistema de pagos & Pago en función del puesto y antigüedad & Incentivos a la productividad y a la calidad \\
\hline Estilo de administración & $\begin{array}{l}\text { Administración semiprofesional. Acuerdos } \\
\text { de tipo familiar }\end{array}$ & $\begin{array}{l}\text { Administración profesional, con personal } \\
\text { capacitado principalmente en Estados Unidos }\end{array}$ \\
\hline Sistema de producción & Producción con énfasis en la oferta & Producción orientada por la demanda \\
\hline Subcontratación & $\begin{array}{l}\text { Poco desarrollada. Escasas relaciones } \\
\text { interempresariales }\end{array}$ & $\begin{array}{l}\text { Desarrollo gradual de la subcontratación y de redes } \\
\text { empresariales }\end{array}$ \\
\hline $\begin{array}{l}\text { Relación entre producción y } \\
\text { distribución }\end{array}$ & $\begin{array}{l}\text { Reducida interacción. Énfasis en los puntos } \\
\text { de venta propios }\end{array}$ & $\begin{array}{l}\text { Fuerte interacción desarrollo de puntos de venta y } \\
\text { otros detallistas }\end{array}$ \\
\hline $\begin{array}{l}\text { Principales modalidades } \\
\text { organizacionales y administrativas }\end{array}$ & $\begin{array}{l}\text { Proceso administrativo. Investigación de } \\
\text { operaciones. Administración por objetivos. } \\
\text { Planeación estratégica }\end{array}$ & $\begin{array}{l}\text { Administración de la calidad total, justo a tiempo, } \\
\text { reingeniería de procesos, cultura corporativa }\end{array}$ \\
\hline
\end{tabular}

Fuente: Montaño (2008)

aún cuando sea demasiado tarde. En la búsqueda de las estrategias de modernización tecnológica los países emergentes de la industria gráfica como resultado del difícil acceso a la modernización de sus procesos han recurrido a las siguientes estrategias (Montaño, 2008) (tabla 4).
Montaño (2008) también asegura que: si bien es cierto no todas las empresas han elaborado estrategias explicitas, las que lo han hecho siguieron un patrón general y poco organizado. Por otra parte, para Hernández (2009) la industria vive un cambio del modelo de sustituciones de importaciones a un modelo exportador y 
¿Qué necesitan las empresas gráficas?

\begin{tabular}{|l|l|}
\hline Actualizarse tecnológicamente & $12 \%$ \\
\hline Se tienen pocos proveedores & $10 \%$ \\
\hline Reducir el alto costo de insumos & $10 \%$ \\
\hline Se necesitan tiempos de entrega cortos & $10 \%$ \\
\hline Se tiene escaso personal capacitado & $10 \%$ \\
\hline Desarrollar metodologías para este sector & $8 \%$ \\
\hline Se necesitan sistemas de calidad & $8 \%$ \\
\hline Buscar nuevas fuentes de financiamiento & $6 \%$ \\
\hline Mejorar el conocimiento del mercado interno & $6 \%$ \\
\hline Falta integración con clientes & $4 \%$ \\
\hline Mejorar su asociatividad & $4 \%$ \\
\hline Enfrentar a la creciente competencia & $2 \%$ \\
\hline Acortar la inseguridad social & $2 \%$ \\
\hline Se tienen servicios insuficientes & $2 \%$ \\
\hline Cubrir el endeudamiento de la industria & $2 \%$ \\
\hline Eliminar el pirateo de personal & $2 \%$ \\
\hline Incrementar su comercialización & $2 \%$ \\
\hline
\end{tabular}

Figura 2. La opinión de empresas socias de institutos gráficos

globalizado con el que da inicio el proceso de modernización. Se trata de un proceso de reestructuración en donde el empresario es el centro de sus propias decisiones, asignándole la responsabilidad de reorganizar a su compañía si quiere ser competitivo. De la Garza (1998) evidencia que a principios del nuevo siglo existen muchas empresas pequeñas y medianas que no han llegado ni siquiera a plantear su modernización. Para De la Hoz (2010), la modernización tecnológica obedece a la producción controlada por computador que ha pasado de la innovación básica radical a la amplia difusión y madurez. Según el autor, esto se debe a dos tendencias: un empuje tecnológico que ha facilitado el uso de los computadores y la presión de la demanda de la industria manufacturera hacia máquinas, equipos y procesos más productivos y flexibles. Finalmente para López y Martínez (2008) la innovación y modernización tecnológica constituyen instrumentos que están generando grandes brechas entre las empresas transnacionales de los países desarrollados contra las pequeñas y medianas empresas de los países en desarrollo, como en el caso de México. En síntesis, la introducción de la modernización tecnológica en la industria gráfica mexicana se ve caracterizada por falta de mecanismos para modernizar los equipos, ausencia de una cultura orientada hacia la innovación, poca apertura hacia los mercados globales, necesidad por el mejoramiento de la eficiencia operacional, falta de capacitación del personal operativo, falta de una visión estratégica y holística de la industria además de una necesidad de nuevas formas para organizar a la producción.
¿Hacia dónde se dirige el sector gráfico?

\begin{tabular}{|l|l|}
\hline Se tiene apoyo incondicional de los proveedores & $40 \%$ \\
\hline Se tiene conocimiento del mercado & $32 \%$ \\
\hline Se tiene apoyo del gobierno federal & $16 \%$ \\
\hline Exportaciones & $12 \%$ \\
\hline
\end{tabular}

¿Cómo es la industria gráfica?

\begin{tabular}{|c|c|}
\hline Se valora a los recursos humanos & $46 \%$ \\
\hline Se tiene conocimiento de procesos & $36 \%$ \\
\hline
\end{tabular}

\begin{tabular}{|l|l|}
\hline Existe calidad en los productos & $18 \%$ \\
\hline
\end{tabular}

¿Qué debe esperar este sector?

\begin{tabular}{|l|l|}
\hline Acelerar su cambio tecnológico & $32 \%$ \\
\hline Introducción de productos sustitutos & $24 \%$ \\
\hline Competencia internacional desleal & $18 \%$ \\
\hline Altos impuestos y excesivos tramites & $10 \%$ \\
\hline Competencia desleal & $8 \%$ \\
\hline Piratería & $6 \%$ \\
\hline Bajo nivel de lectura & $2 \%$ \\
\hline
\end{tabular}

\section{Metodología-fase cualitativa}

La opinión de los organismos e institutos gráficos

En una primera etapa denominada como cualitativa, se realizaron entrevistas abiertas con el personal directivo de una muestra representativa de 40 unidades económicas que han implantado procesos de modernización tecnológica con éxito. Los resultados de estas entrevistas pueden visualizarse en los siguientes cuadros de la figura 2.

\section{La observación directa en la industria gráfica}

Para la muestra original de 40 unidades económicas y en una segunda etapa se aplicó la herramienta de observación directa, participando en revisiones a la planta y en las juntas de operación de estas empresas. La información fue registrada en el formato del Anexo "A" y analizada a través del software Atlas.ti Versión 7. Los resultados de las ideas y conceptos más utilizados por el personal son los que se detallan en la tabla 5.

De la tabla 5 se puede apreciar que las ideas y conceptos más empleados tienden a ser clasificados en cuatro categorías: modernización de procesos con $43.96 \%$, dirección y equipos con $30.35 \%$, productividad con $24.25 \%$ e innovación con $1.44 \%$.

\section{El punto de vista de la industria gráfica}

En una tercera etapa se aplicó la herramienta de entrevista abierta tanto a directivos como a operativos de la 
Tabla 5. La Observación directa. Con información de empresas socias de institutos gráficos

\begin{tabular}{|c|c|c|c|c|c|c|c|}
\hline \multicolumn{2}{|c|}{ Modernización de procesos } & \multicolumn{2}{|c|}{ Dirección y equipos } & \multicolumn{2}{|c|}{ Productividad } & \multicolumn{2}{|c|}{ Innovación } \\
\hline Proceso & 19.70 & Trabajo & 6.06 & Reducción & 6.06 & Ideas & 1.44 \\
\hline Producción & 10.61 & Dirección & 4.55 & Desperdicio & 3.03 & & \\
\hline Procesos & 6.06 & Concientización & 3.03 & Indicadores & 3.03 & & \\
\hline Neurálgicos & 4.55 & Equipos & 3.03 & Materiales & 3.03 & & \\
\hline Estandarización & 1.52 & Estrategia & 1.52 & Productividad & 3.03 & & \\
\hline \multirow[t]{8}{*}{ TG } & 1.52 & Estratégica & 1.52 & Waste & 3.03 & & \\
\hline & & Liderazgo & 1.52 & Desperdicios & 1.52 & & \\
\hline & & Organización & 1.52 & Mejora & 1.52 & & \\
\hline & & Participación & 1.52 & & & & \\
\hline & & Personal & 1.52 & & & & \\
\hline & & Planeación & 1.52 & & & & \\
\hline & & Planificación & 1.52 & & & & \\
\hline & & Subgrupos & 1.52 & & & & \\
\hline Total & $43.96 \%$ & Total & $30.35 \%$ & Total & $24.25 \%$ & Total & $1.44 \%$ \\
\hline
\end{tabular}

muestra original. La información fue registrada en el formato del Anexo "B" y analizada a través del software Atlas.ti Versión 7. Los resultados de las ideas y conceptos más utilizados son los que se muestran en la tabla 6.

De la tabla anterior se puede apreciar que las ideas y conceptos más utilizados por el personal gráfico es tendiente a ser clasificado en cuatro categorías: modernización de procesos con $56.43 \%$, dirección y equipos con $28.71 \%$, productividad con $8.91 \%$ e innovación con $5.95 \%$.

\section{Metodología-fase cuantitativa}

El análisis de evaluación sumaria

Del análisis cualitativo y de acuerdo con la clasificación de las cuatro categorías antes descritas se determinó que las variables y detonadores que debería contemplar el modelo son:

a) Modernización de procesos = modernización tecnológica. Entendida como la capacidad de la empresa para renovarse integrando a sus procesos convencionales las tecnologías de la información y la comunicación (TIC's).

b) Dirección y equipos = liderazgo estratégico. Entendida como la capacidad de la empresa para pensar en forma estratégica, mantener la flexibilidad y trabajar con los demás para iniciar cambios que generen un mejor futuro.

c) Productividad = eficiencia operacional. Entendida como la capacidad de la empresa para reducir sus costos de operación al mismo tiempo que se incrementa la calidad de sus productos. d) Innovación = Innovación prospectiva. Entendida como la capacidad de la empresa para estimular la creatividad de su personal estimando un futuro posible e ideal.

El siguiente análisis (Anexo " $\mathrm{C}^{\prime \prime}$ ) cuantitativo se trata de la aplicación de un cuestionario de evaluación sumaria tipo Likert de 5 categorías que fue practicado a personal experto, administrativo y operativo del espacio muestral original, para determinar la actitud o predisposición a los elementos más significativos del modelo. Los resultados presentan fiabilidad con un Alfa de Cronbach de 0.8 (Anexo "D") y son los que se muestran en la figura 3.

Lo anterior determina que la eficiencia operacional ha contribuido con $26.39 \%$, la modernización tecnológica con $25.70 \%$, seguido del liderazgo estratégico $24.46 \%$ y finalmente la innovación prospectiva con $23.45 \%$.

\section{La metodología de modernización tecnológica}

De acuerdo con las observaciones realizadas, así como de entrevistas a través de cuestionarios abiertos y medición de actitudes se propone a continuación una metodología para la modernización tecnológica que le permitirá a la industria de las artes gráficas preparar y orientar a sus procesos operativos y administrativos estratégicamente hacia un futuro digitalizado. La metodología de modernización tecnológica se compone de doce puntos que bien pueden sintetizarse en seis etapas clave: la formación de los grupos de trabajo y estandarización de las soluciones (liderazgo estratégico); revisión física de la planta y medición de los indicadores de productividad (eficiencia operacional); solución de las 
Tabla 6. El punto de vista de la industria gráfica. Con información de empresas socias de institutos gráficos

\begin{tabular}{|c|c|c|c|c|c|c|c|}
\hline \multicolumn{2}{|c|}{ Modernización de procesos } & \multicolumn{2}{|c|}{ Dirección y equipos } & \multicolumn{2}{|c|}{ Productividad } & \multicolumn{2}{|c|}{ Innovación } \\
\hline Procesos & 8.91 & Equipos & 6.93 & Tiempos & 3.96 & Ideas & 1.99 \\
\hline Impresión & 7.92 & Trabajo & 6.93 & Desperdicios & 2.97 & Flexibilización & 0.99 \\
\hline Tecnología & 4.95 & Organización & 4.95 & Productividad & 1.98 & Innovando & 0.99 \\
\hline Tecnologías & 4.95 & Equipo & 1.98 & & & Innovar & 0.99 \\
\hline Modernización & 3.96 & Simplificar & 1.98 & & & Reinventar & 0.99 \\
\hline Software & 2.97 & Capacitarse & 1.98 & & & & \\
\hline Actualización & 1.98 & Dirección & 0.99 & & & & \\
\hline Hardware & 1.98 & Estrategia & 0.99 & & & & \\
\hline Maquinas & 1.98 & Estratégica & 0.99 & & & & \\
\hline Renovación & 1.98 & Liderazgo & 0.99 & & & & \\
\hline Sistemas & 1.98 & & & & & & \\
\hline Vanguardia & 1.98 & & & & & & \\
\hline Actualizado & 1.98 & & & & & & \\
\hline Actualizarnos & 1.98 & & & & & & \\
\hline Automatizada & 1.98 & & & & & & \\
\hline Computadora & 0.99 & & & & & & \\
\hline Digital & 0.99 & & & & & & \\
\hline Internet & 0.99 & & & & & & \\
\hline Modernizamos & 0.99 & & & & & & \\
\hline TG & 0.99 & & & & & & \\
\hline Total & $56.43 \%$ & Total & $28.71 \%$ & Total & $8.91 \%$ & Total & $5.95 \%$ \\
\hline
\end{tabular}

barreras de proceso y la administración para las nuevas ideas (innovación prospectiva). La aplicación sistemática de estas seis etapas clave conduce a la "modernización tecnológica" tal como lo demuestra el caso de estudio que se presenta en el siguiente apartado (figura 4).

\section{Un caso de éxito}

\section{Antecedentes}

"La empresa litográfica", como se llamará de aquí en adelante, es una sociedad anónima de capital variable, cuyo giro es la litografía, esta puede ser clasificada como mediana empresa (120 trabajadores, entre operativos y administrativos), comienza labores a finales de los años 60 en los primeros talleres de la colonia Balbuena $1^{\underline{a}}$ sección en la zona conurbada del Distrito Federal. Entre sus principales características se encuentran:

Localización: Estado de México Distribución de planta: por procesos

Tipo de organización: vertical

Infraestructura: 15 prensas, 6 colectoras y equipo de acabado

Personal técnico y de apoyo: 67

Principales productos: impresión fija y variable

Principales proveedores: GP, KK, Sandvik y Sicpa
El 11 de enero del 2011 se celebró una reunión extraordinaria en la sala de juntas de la planta para que cada uno de los departamentos presentara a la dirección los resultados del año 2010. Aún cuando algunos departamentos evidenciaban limitadas mejoras, los indicadores del departamento de producción en nada eran alentadores: el tiempo de ciclo total para una orden promediaba 7 días, el desperdicio de papel global se disparaba en $21 \%$ del total consumido, los tiempos de arreglo se retrasaban hasta 1 día y las ordenes de

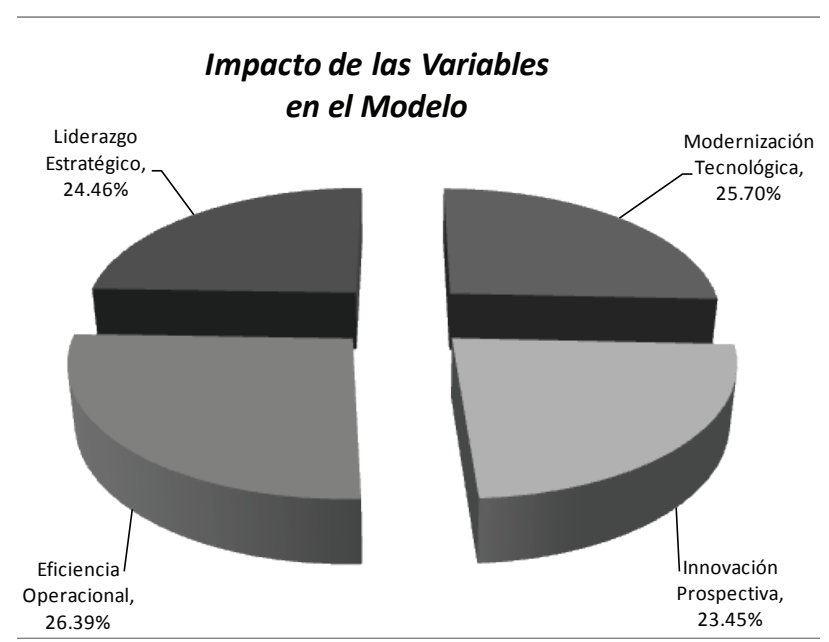

Figura 3. Impacto de las variables en el modelo. Con información de empresas socias de institutos gráficos 


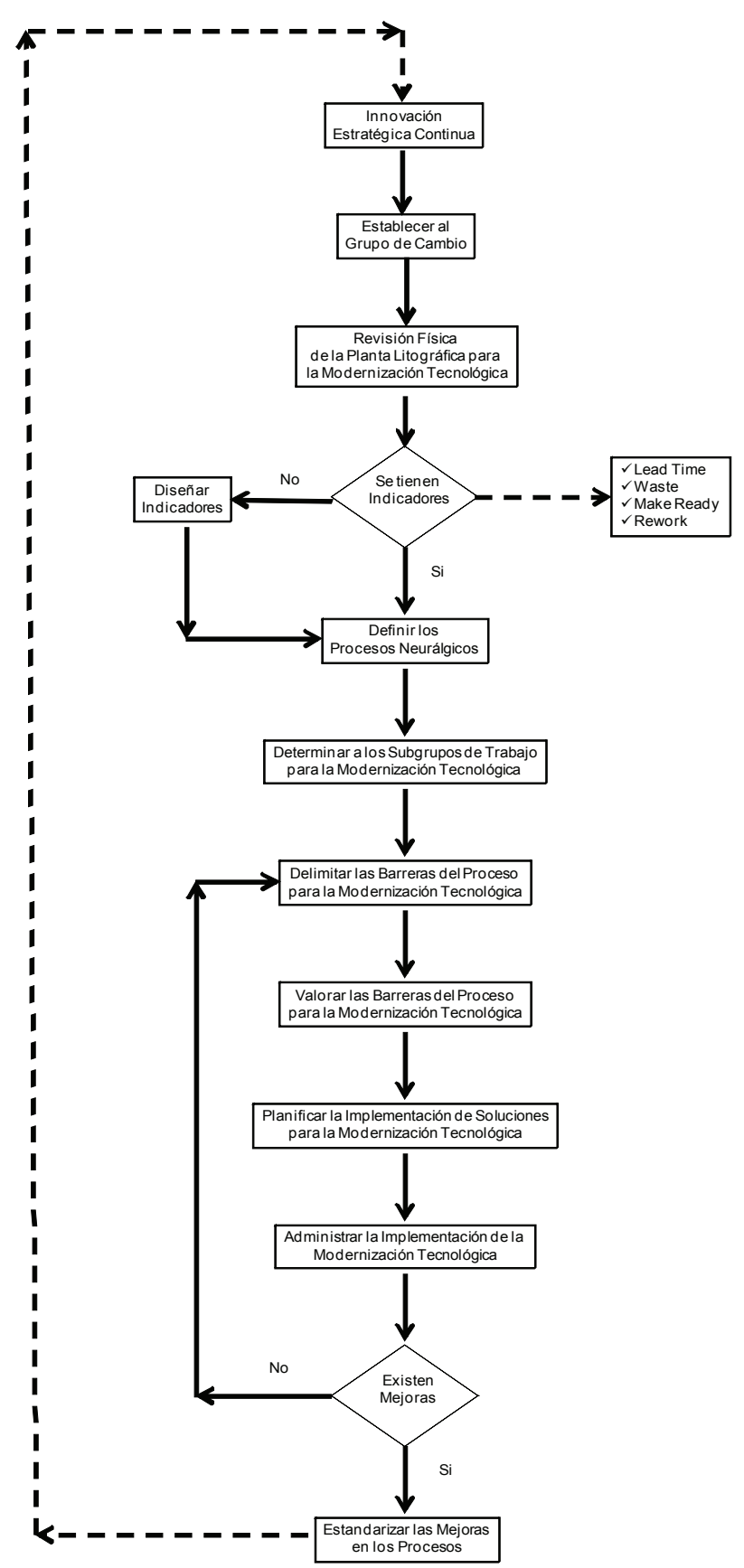

Figura 4. Metodología de modernización tecnológica

servicio terminadas tenían que ser retrabajadas en 5\% del volumen total. El departamento de producción evidenciaba serios problemas en todas las áreas de trabajo: el mantenimiento correctivo era constante, los errores de la preprensa hacían que se pararan los equipos continuamente, la planeación de la producción demandaba constantes ajustes que obligaban a retrasar las ordenes, a pesar de los controles de calidad los reportes de queja de los clientes eran frecuentes, además de que el clima laboral vulneraba la motivación del personal. Días más tarde causaron baja la dirección general, las gerencias de producción y planeación además de ocho cargos operativos.

\section{Establecimiento del grupo de cambio}

Hacia finales de enero de 2011 se releva a la dirección general y a los ocho cargos operativos, la tarea no fue fácil. Para las semanas siguientes la dirección general decidió elevar a rangos staff a las superintendencias de producción y planeación, hombres que por su responsabilidad, honestidad, liderazgo y experiencia no tardaron en ser seleccionados para encabezar la transformación de la empresa, simplificando a la organización en grupos: grupo de cambio, grupo de ventas, grupo de expedición, grupo de soporte, grupo de administración, grupo de innovación y grupo de operaciones.

Para inicios de febrero de 2011 en una primera reunión del aparato directivo y administrativo se realizó la planeación estratégica para la transformación de la planta. Este grupo de cambio desarrolló un total de once objetivos financieros y estratégicos entre los que destaca el objetivo Núm. 7 "Maximizar la excelencia operacional de los procesos a través de la modernización de la planta".

\section{Revisión física de la planta litográfica}

Posteriormente el 10 de febrero de 2011 se realizaron los tres primeros recorridos aleatorios en los tres diferentes turnos sin un previo aviso y sin cuestionar para juzgar el actuar de las distintas áreas operativas. Algunos de los problemas que se encontraron se muestran en la tabla 7.

\section{Determinación de los indicadores}

El grupo de cambio diseñó los indicadores de productividad entre los que se pueden destacar los datos de la tabla 8.

\section{Procesos neurálgicos}

De acuerdo con un análisis (efectuado por el grupo de cambio) de las funciones productivas, los procesos neurálgicos que limitan el mejoramiento de los indicadores mostrados en la tabla 6 son los que se muestran en la tabla 9.

De la tabla 9, las actividades de las áreas de ventas, planeación, producción y embarques fueran cataloga- 
Tabla 7. Revisión física a la empresa litográfica

\begin{tabular}{|c|c|c|c|c|c|c|}
\hline \multicolumn{2}{|c|}{$\begin{array}{c}\text { Primer turno } \\
\text { (Hora de inicio : 8:10 am - Hora de termino } \\
\text { 8:40 am) }\end{array}$} & \multicolumn{3}{|c|}{$\begin{array}{c}\text { Segundo turno } \\
\text { (Hora de inicio : } 18: 30 \mathrm{pm}-\text { Hora de } \\
\text { termino : } 7: 45 \mathrm{pm} \text { ) }\end{array}$} & \multicolumn{2}{|c|}{$\begin{array}{c}\text { Tercer turno } \\
\text { (Hora de inicio : 2:30 am - Hora de termino } \\
\text { 3:45 am) }\end{array}$} \\
\hline \multicolumn{2}{|c|}{$\begin{array}{l}\text { 1.- Tres clientes en el área de almacenes } \\
\text { esperando por producto terminado } \\
\text { 2.- } 840 \mathrm{Kg} \text { de desperdicio de papel impreso } \\
\text { y en blanco } \\
\text { 3.- Cuatro de los equipos en espera por } \\
\text { MakeReady } \\
\text { 4.- Dos de los equipo en mantenimiento } \\
\text { correctivo } \\
\text { 5.- Tres de los equipos en espera por } \\
\text { aclaraciones de preprensa y/o planeación }\end{array}$} & \multicolumn{3}{|c|}{$\begin{array}{l}\text { 1.- Tres cuellos de botella por tiros largos de } \\
\text { prensas a colectoras } \\
\text { 2.- Un equipo con problemas en tono de } \\
\text { tinta base pantone } \\
\text { 3.- Un equipo en espera de material de } \\
\text { cortadoras } \\
\text { 4.- Tres equipos en espera de Vo. Bo } \\
\text { 5.- Un equipo con problemas con una } \\
\text { especialidad }\end{array}$} & \multicolumn{2}{|c|}{$\begin{array}{l}\text { 1.- Tres equipos en espera por aclaraciones } \\
\text { 2.- Dos fugas de aire por problemas en } \\
\text { mangueras de aspersión } \\
\text { 3.- Supervisor con dificultades para atender } \\
\text { a todos los equipos } \\
\text { 4.- Un equipo en paro por rotura de papel } \\
\text { 5.- Un equipo continúa con problemas en } \\
\text { una especialidad }\end{array}$} \\
\hline $\begin{array}{l}\text { Tiempo de ciclo } \\
\text { (Lead Time) }\end{array}$ & Desperdicio & & & & $\begin{array}{l}\text { Arreglos } \\
\text { (MakeReady) }\end{array}$ & \\
\hline $\begin{array}{l}\text { Tiempo que tarda una } \\
\text { orden de servicio desde } \\
\text { que se coloca por el cliente } \\
\text { hasta que se recibe por } \\
\text { este }\end{array}$ & $\begin{array}{l}\text { Se trata del des } \\
\text { de papel genera } \\
\text { por los arreglos } \\
\text { máquina y los e } \\
\text { producción }\end{array}$ & $\begin{array}{l}\text { perdicio } \\
\text { do } \\
\text { de } \\
\text { rrores de }\end{array}$ & $\begin{array}{l}\text { Contabiliza las órdenes } \\
\text { de servicio que por } \\
\text { la naturaleza de sus } \\
\text { defectos tienen que } \\
\text { ser reprocesadas o } \\
\text { reajustadas }\end{array}$ & $\begin{array}{l}\text { Es el tie } \\
\text { cronom } \\
\text { que se } \\
\text { orden c } \\
\text { hasta q } \\
\text { primer } \\
\text { en buer }\end{array}$ & $\begin{array}{l}\text { iempo de arreglo } \\
\text { metrado desde } \\
\text { comienza una } \\
\text { de servicio } \\
\text { que se obtiene la } \\
\text { ra hoja impresa } \\
\text { n estado }\end{array}$ & $\begin{array}{l}\text { Se trata de la longitud } \\
\text { que recorre la orden } \\
\text { de servicio desde que } \\
\text { ingresa a planta hasta que } \\
\text { es colocada en el área de } \\
\text { entrega de producto }\end{array}$ \\
\hline $\begin{array}{l}\text { Lead Time }=\text { fecha de } \\
\text { entrega de la orden - } \\
\text { Fecha de recibo de la } \\
\text { orden = (Días) }\end{array}$ & $\begin{array}{l}\text { Waste }=\text { desperc } \\
\text { Kg de papel en } \\
\text { consumo en } \mathrm{Kg} \\
100=(\%)\end{array}$ & $\begin{array}{l}\text { licio en } \\
\text { planta/ } \\
\text { global * }\end{array}$ & $\begin{array}{l}\text { ReWork = Núm. de } \\
\text { órdenes de servicio } \\
\text { retrabajadas/Núm. de } \\
\text { órdenes servidas * } 100 \\
=(\%)\end{array}$ & $\begin{array}{l}\text { MakeRe } \\
\text { minuto } \\
\text { hoja im } \\
\text { estado } \\
\text { inicio d } \\
\text { servicic }\end{array}$ & $\begin{array}{l}\text { oady }=\text { tiempo en } \\
\text { os de la primera } \\
\text { npresa en buen } \\
\text { - tiempo de } \\
\text { de la orden de } \\
\text { o }=(\mathrm{min})\end{array}$ & $\begin{array}{l}\text { Transport }=\mathrm{L} 1+\mathrm{L} 2+\mathrm{L} 3+ \\
\ldots \mathrm{Ln}=(\mathrm{m})\end{array}$ \\
\hline
\end{tabular}

Tabla 9. Procesos neurálgicos de la empresa litográfica

\begin{tabular}{llll}
\hline \multicolumn{1}{c}{ Ventas } & \multicolumn{1}{c}{ Planeación } & \multicolumn{1}{c}{ Producción } & \multicolumn{1}{c}{ Embarques } \\
\hline Ingreso de ordenes & Archivo & Preliminares & Distribución \\
Costeo & Revisión de ordenes & Prensas & \\
Marketing & Materiales & Mantenimiento & \\
& Compras & Servicio técnico & \\
\hline
\end{tabular}

das como funciones críticas y de aquí que hiciera necesaria la creación de subgrupos de trabajo para resolver la problemática de la empresa.

\section{Delimitar a los subgrupos de trabajo}

A medida que la planta se transformaba, se integraron nuevos subgrupos de trabajo bajo un enfoque de liderazgo participativo (tabla 10).

\section{Delimitación las barreras del proceso}

Para este punto se elaboró una tabla sencilla (figura 5) y codificada de las diez barreras que limitan la modernización y productividad de la planta.

\section{Valoración las barreras del proceso}

Bajo un esquema impacto vs dificultad se seleccionaron las principales barreras por remover (figura 6).

Planificación de la implementación de soluciones

En esta misma secuencia fueron implementadas soluciones que permitieran eliminar las barreras que limitaban la modernización y productividad de la planta (figura 7).

Administración de la implementación de ideas

A medida que las barreras se removían, un tablero mostraba la implementación de las ideas completadas, en pro- 
Tabla 10. Subgrupos de trabajo

\begin{tabular}{|c|c|c|c|c|c|}
\hline \multicolumn{2}{|c|}{ Pre-prensa } & \multicolumn{2}{|c|}{ Prensa } & \multicolumn{2}{|c|}{ Pos-prensa } \\
\hline Cargo & Roll & Cargo & Roll & Cargo & Roll \\
\hline $\begin{array}{l}\text { Supervisor de } \\
\text { producción }\end{array}$ & Titular & Jefe de Prensas & Titular & $\begin{array}{l}\text { Supervisor de } \\
\text { materiales }\end{array}$ & Titular \\
\hline Prensista " $\mathrm{A}$ " & Especialista & Colectorcita "A" & Especialista & Compras & Especialista \\
\hline Técnico & Técnico & Inspector de calidad & Técnico sspecialista & Ayudante general & Técnico \\
\hline $\begin{array}{l}\text { Inspector de } \\
\text { preliminares }\end{array}$ & Soporte & $\begin{array}{l}\text { Jefe de } \\
\text { mantenimiento }\end{array}$ & Soporte & Recibo de materiales & Soporte \\
\hline Ventas & Soporte & $\begin{array}{l}\text { Administrador } \\
\text { Embarque }\end{array}$ & Soporte & Planeación & Soporte \\
\hline
\end{tabular}

Fuente: Elaboración propia basada en información de la "la firma"

\begin{tabular}{|c|c|c|c|}
\hline \multicolumn{4}{|c|}{ BARRERAS DE PROCESO } \\
\hline \multicolumn{4}{|c|}{$\begin{array}{l}\text { Fecha: } 2011 \\
\text { Integrantes: Grupo de Operaciones }\end{array}$} \\
\hline COD. & ITEM & BARRERA & OBSERVACIONES \\
\hline 1 & A & $\begin{array}{l}\text { No se tiene una redistribución de planta } \\
\text { que mejore el flujo en el proceso }\end{array}$ & Layout Proceso \\
\hline 2 & B & $\begin{array}{l}\text { No se posee una simplificación real de } \\
\text { las operaciones que permitan un flujo } \\
\text { rápido y continuo de las operaciones }\end{array}$ & Lean \\
\hline 3 & c & $\begin{array}{l}\text { Las áreas praductivas están organizadas } \\
\text { bajo un esquema de producción en } \\
\text { masa que limita el tiraje corto de } \\
\text { producción }\end{array}$ & Brown Field \\
\hline 4 & D & $\begin{array}{l}\text { El área de ventas necesita comunicación } \\
\text { y capacitación para ingresar una orden } \\
\text { libre de errores }\end{array}$ & Diseñadores \\
\hline 5 & E & $\begin{array}{l}\text { El deteriorado ambiente organizacional } \\
\text { hace que el personal no desarrolle sus } \\
\text { actividades normalmente }\end{array}$ & Clima Laboral \\
\hline 6 & $\mathrm{~F}$ & $\begin{array}{l}\text { Existen muchos retardas y quejas por } \\
\text { igualación de color en las ordenes de } \\
\text { producción }\end{array}$ & Densitómetras \\
\hline 7 & G & $\begin{array}{l}\text { El constante número de especialidades y } \\
\text { tiraje corto demanda mayores } \\
\text { habilidades del personal operativo }\end{array}$ & Tiros cortos \\
\hline 8 & $\mathbf{H}$ & $\begin{array}{l}\text { No se cumple con una estandarización } \\
\text { real de las procesas de fabricación }\end{array}$ & ISO 9000 \\
\hline 9 & 1 & $\begin{array}{l}\text { Se tiene un alto índice de desperdicio en } \\
\text { prensas, colectoras y acabados }\end{array}$ & Muda \\
\hline 10 & J & $\begin{array}{l}\text { Se tiene un alto índice de espera por } \\
\text { arreglos de tirajes cortos }\end{array}$ & Make Ready \\
\hline
\end{tabular}

Figura 5. Barreras de proceso. Con información de "la empresa litográfica"

cesos, en espera, las nuevas barreras, así como las ideas que requerían ser analizadas por la dirección (figura 8). Implementación de soluciones

Entre las soluciones implementadas se encuentran las siguientes:

Aplicación de técnicas SMED. Esta es una medida de arreglos rápidos, la cual se ha implementado en todos los equipos de todas las áreas productivas. Esta técnica consiste en colocar marcas en las unidades de impresión para realizar la puesta a punto de blankets y placas.

Aplicación de técnicas POKA-YOKE. Se trata de medidas que evidencien los errores. En la planta se dispuso de contenedores de desperdicio prácticamente recortados a la mitad, permitiendo psicológicamente que el operador se concientice de sus errores. También se colo- caron banderas y etiquetas en los rollos de impresión de buena y mala calidad.

Discurso motivacional de los directivos. A principios del año 2011 se paró la producción por unas horas, en el centro de las instalaciones productivas los directivos de la planta emitieron un breve discurso en el que se comprometían básicamente en los siguientes puntos: no más despidos, empleo seguro, desarrollo de capacidades, incentivos por productividad, una dirección ética.

Estandarización de procedimientos. Se trataba de mantener una rigidez puntual en los procesos de manufactura, pero sin olvidar la posibilidad de experimentar nuevas prácticas y soluciones, flexibilizando y permitiendo actualizar las mejores de la planta.

Técnicas para un mejor manejo de materiales. Básicamente se dispuso de tres técnicas para un mejor manejo de materiales: El uso de mejores empaques para papeles especiales y el uso de tarimóvil.

Campaña de reducción del desperdicio. En esta campaña se atacaron las áreas de oportunidad como el papel de reúso para arreglos, programa de mantenimiento preventivo a equipos y mejores sistemas para manejo de materiales.

Desarrollo en el área de ventas. Anteriormente la orden de servicio se tomaba de forma manual y se ingresaba a través del denominado docket de producción, sobre el cual se plasmaban todas las especificaciones del trabajo, sin embargo esto orillaba a constantes inconsistencias en el proceso que muchas veces culminaban con múltiples retrasos o el paro de prensas. Actualmente el área de ventas tiene un perfil de diseñador gráfico y dispone de un ordenador portátil para dejar a punto la orden de producción libre de errores e ingresarla a planta.

Redistribución de planta: La primera redistribución de planta lineal permitió un flujo más rápido de las órdenes que culminó más tarde en una redistribución celular como se muestra en la figura 9. 


\section{MAPA IMPACTO - DIFICULTAD}

\section{IMPACTO}

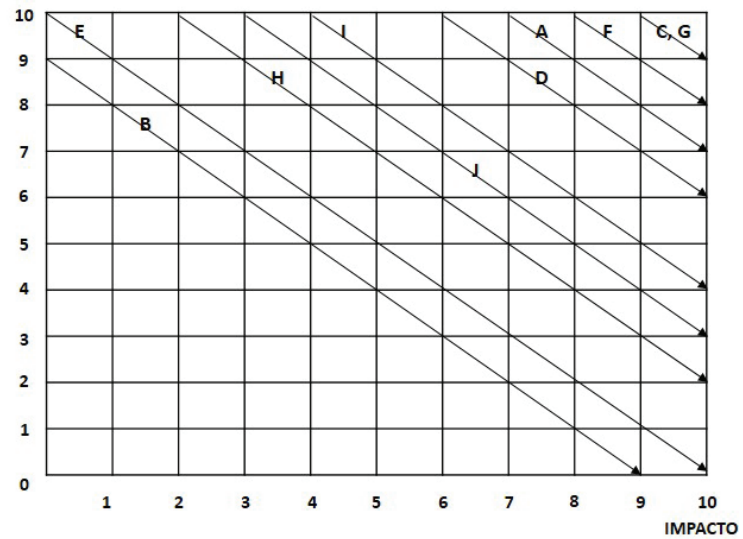

SOLUCIÓN DE BARRERAS DE PROCESO

\begin{tabular}{|c|l|c|c|}
\hline No & \multicolumn{1}{|c|}{ BARRERA } & \multicolumn{1}{|c|}{ I. } & D. \\
\hline A & Es necesario la implementación de una redistribución de planta & 10 & 5 \\
\hline B & Aplicar técnicas que simplifiquen las operaciones en planta: IIT, SMED, POKAYOKE & 5 & 2 \\
\hline C & Organización de la planta bajo un esquema celular y de tecnología de grupos & 10 & 10 \\
\hline D & El área de ventas deberá tener un perfil de diseñador gráfico y auxiliado de una PC & 9 & 5 \\
\hline E & Es necesario una charla motivacional y abierta de los directivos a las áreas operativas & 10 & 1 \\
\hline F & Se hace necesario el uso de densitómetros para la igualación de color en prensas & 10 & 9 \\
\hline G & Aplicación de un programa de capacitación para tener operadores multifuncionales & 10 & 10 \\
\hline H & Es necesaria la estandarización de los procedimientos de planta & 9 & 4 \\
\hline I & Implementar una campaña de reducción del desperdicio en todas las áreas operativas & 10 & 5 \\
\hline J & Es necesaria la adopción de técnicas para un mejor manejo de materiales & 10 & 7 \\
\hline
\end{tabular}

Figura 6. Mapa impacto-dificultad. Con información de "la empresa litográfica"

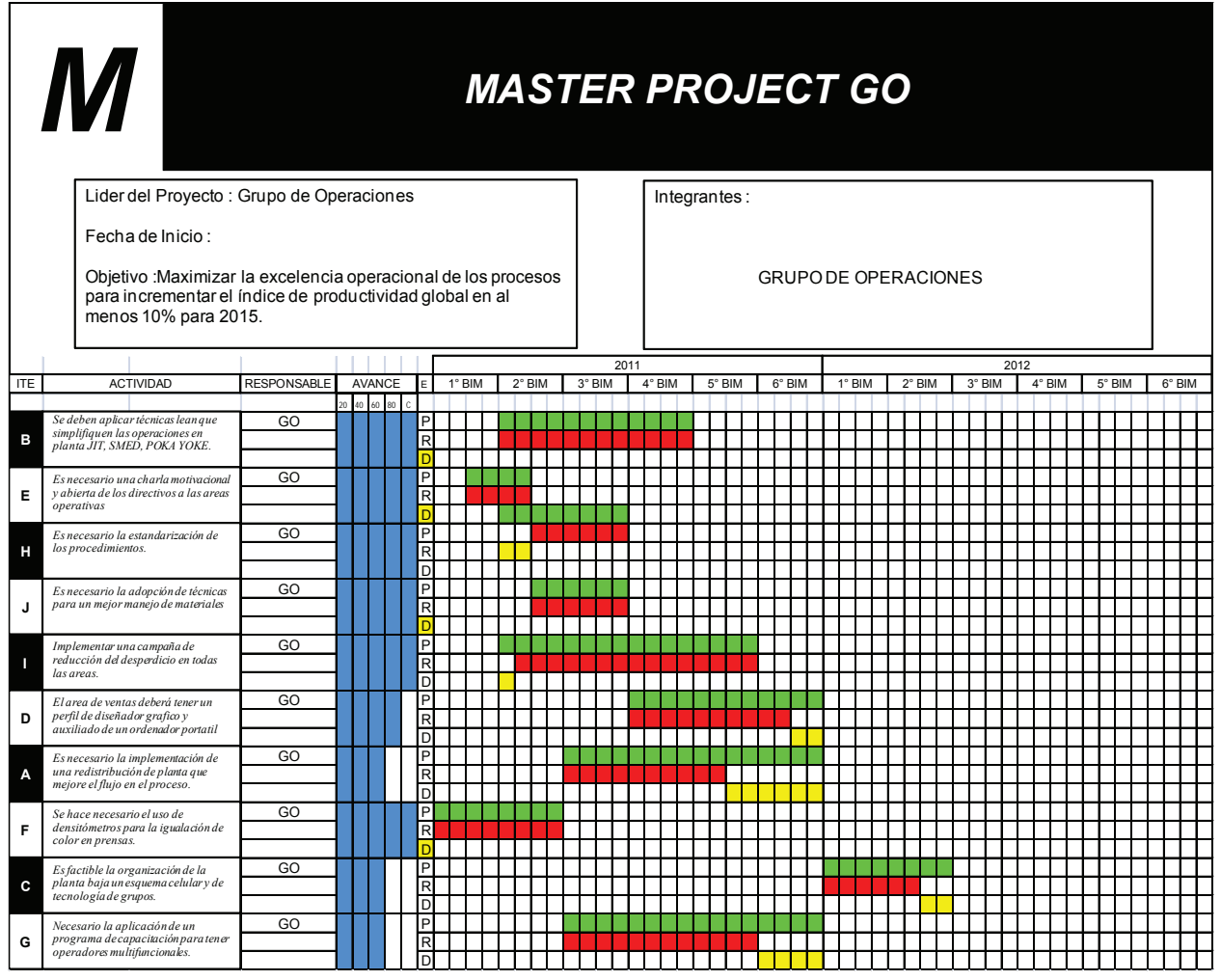

Figura 7. Planificación para la implementación de las soluciones. Con información de "la empresa litográfica" 


\section{ADMINISTRACIÓN DE ACCIONES EN PROCESO}
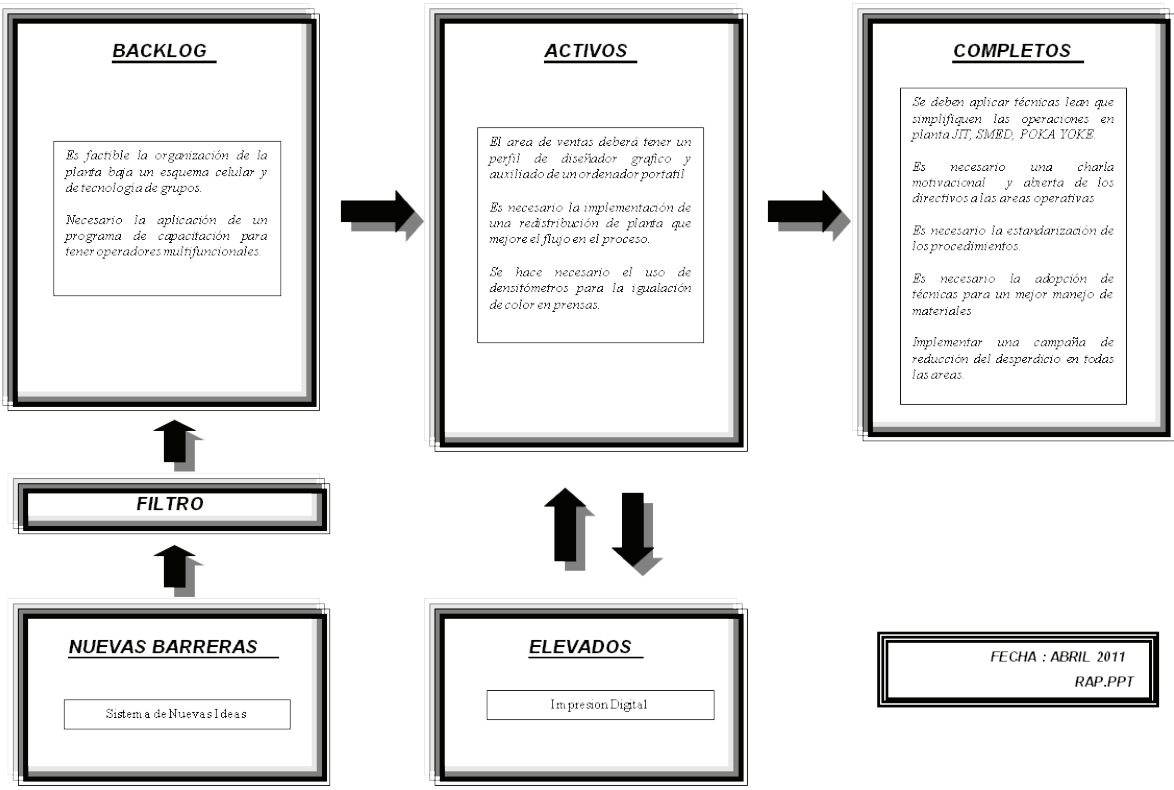

Figura 8. Administración de la implementación de soluciones. Con información de "la empresa litográfica"
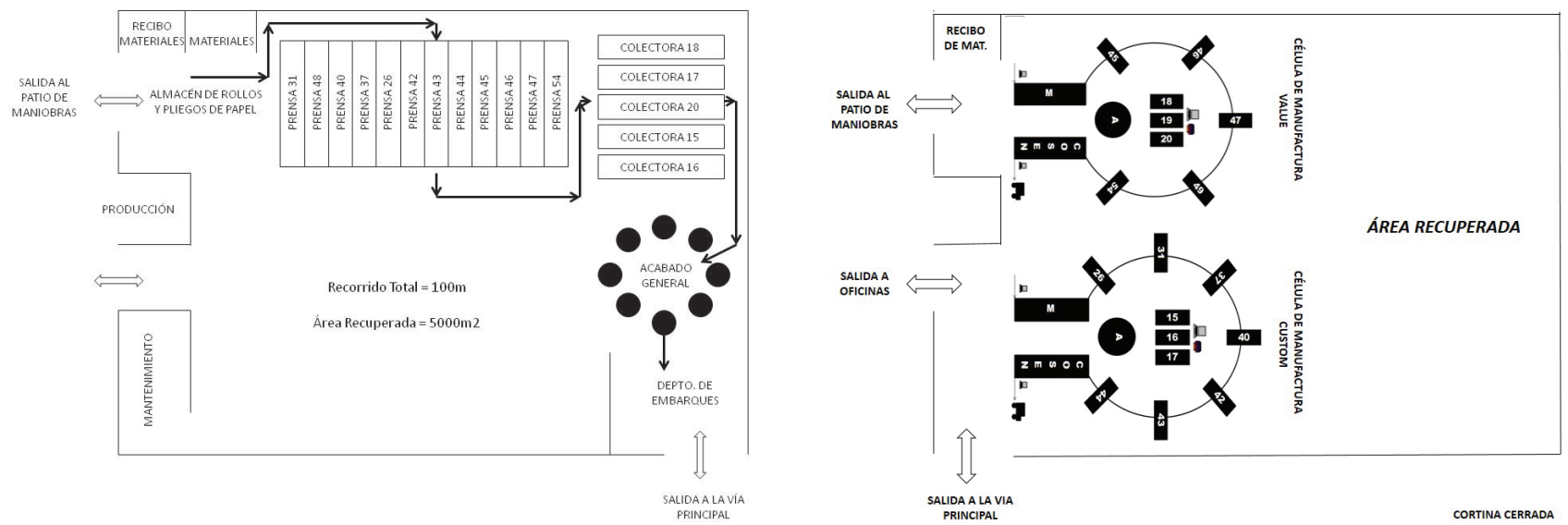

Figura 9. Primera y segunda redistribución de planta. Con información de "la empresa litográfica" 
Para la redistribución de planta celular se utilizó la herramienta de tecnología de grupos para desarrollar dos grandes familias: la de producto tradicional o custom y la de producto de valores o value. Se desarrollaron dos células de trabajo en " $\mathrm{O}$ ", que operan con almacenes independientes y codificados según las rutas para su distribución.

Sistema de manufactura litográfico: la fuerza de ventas realiza la función de diseñador, una vez que se obtiene la primera muestra y el Vo. Bo. de la orden de servicio, con la ayuda de la base de datos, se ingresa el pedido en la preprensa, el cual se encarga de preparar los insumos para producción, por su parte producción alista las células de trabajo -custom o value- y realiza los arreglos pertinentes para la corrida de producción. Una vez concluida la orden se coloca en los racks de distribución COSEN ( $\mathrm{C}=$ centro, $\mathrm{O}=$ oeste, $\mathrm{S}=$ sur, $\mathrm{E}=$ este y $\mathrm{N}=$ norte) para ser remitidos al cliente y en su caso, entregados en la puerta de la planta (figura 10).

Programa de multifuncionalidad: mensualmente se abren talleres de capacitación para el personal operativo y administrativo en el área de pegamentos, planchas, mantillas, sustratos, tintas, prensas, matrices, colectoras, acabados e incluso idiomas. El personal que imparte estos cursos son los mismos proveedores o per- sonal de mayor experiencia, los cursos no tienen costo y se imparten dentro de la planta como parte del compromiso de la dirección.

Sistema de nuevas ideas: actualmente se trabaja sobre un sistema que recompense y administre las nuevas ideas en la planta.

\section{Existen mejoras al proceso}

Las mejoras que se han registrado se pueden visualizar en la tabla 11.

\section{Estandarizar las soluciones}

En primer término los indicadores se han llevado hasta la planta misma, para que de forma sencilla y clara se entienda por los operativos, administrativos y directivos. Como si se tratara del indicador analógico de un avión se ha dividido en cuatro grandes áreas: tiempo de ciclo, desperdicio, retrabajos y arreglos, conjuntamente con el global de planta. Los colores emulan los de un semáforo, verde $=$ condiciones normales, anaranjado $=$ condiciones preventivas, rojo $=$ condiciones anormales. Para las demás áreas se han estandarizado las soluciones de la tabla 12.

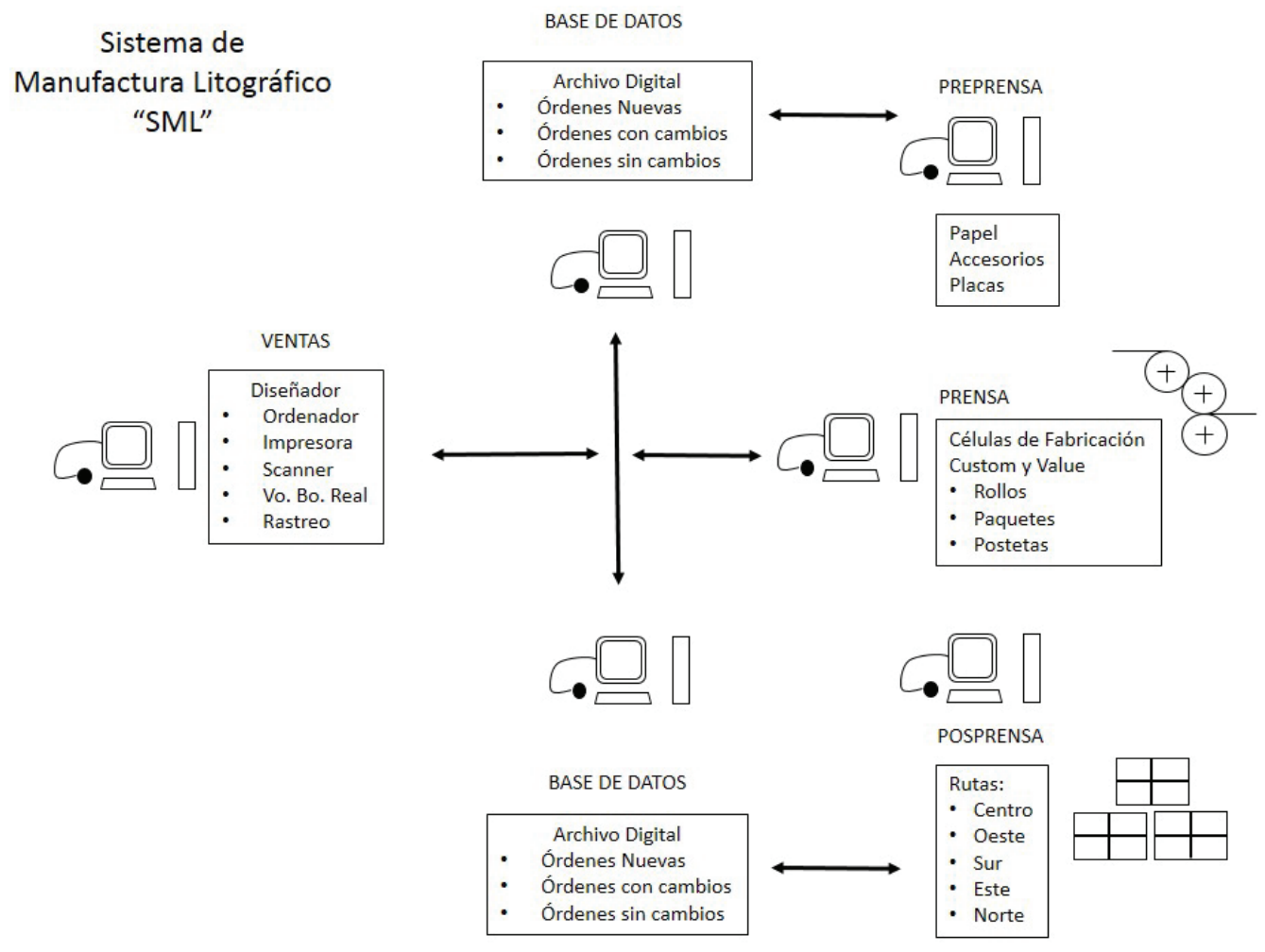

Figura 10. Sistema de manufactura litográfico. Con información de "la empresa litográfica" 
Tabla 11. Indicadores de excelencia operacional 2011. Con información de "la empresa litográfica"

\begin{tabular}{lcccc}
\hline \multicolumn{1}{c}{ Indicador } & Año & Año & Año & Año \\
\hline Transport (metros) & 2008 & 2009 & 2010 & 2011 \\
Rework (\%) & 200 & 200 & 200 & 20 \\
Make Ready (hrs) & 4.8 & 5.2 & 5.1 & 0.5 \\
Waste (\%) & 36 & 28.8 & 26.4 & 0.48 \\
Lead Time (día) & 20.2 & 22.1 & 21.2 & 4.3 \\
\hline
\end{tabular}

Tabla 12. Estandarización

\begin{tabular}{|c|c|c|}
\hline Acabados & Prensas y colectoras & Materiales \\
\hline $\begin{array}{l}\text { a) Procedimiento para arreglo de } \\
\text { máquina }\end{array}$ & $\begin{array}{l}\text { a) Procedimiento para arreglo de } \\
\text { máquina }\end{array}$ & $\begin{array}{l}\text { a) Procedimiento para empaques de } \\
\text { papel KK }\end{array}$ \\
\hline $\begin{array}{l}\text { b) Procedimiento para el uso de papel } \\
\text { impreso y opaco para arreglo }\end{array}$ & $\begin{array}{l}\text { b) Generación de nuevo puesto } \\
\text { coordinador de materiales }\end{array}$ & $\begin{array}{l}\text { b) Procedimiento de Inspección de recibo } \\
\text { de materiales }\end{array}$ \\
\hline $\begin{array}{l}\text { c) Make Ready estático de unidades de } \\
\text { goma, foliadores y corte }\end{array}$ & $\begin{array}{l}\text { c) Make Ready estático de unidades de } \\
\text { impresión y humectación }\end{array}$ & $\begin{array}{l}\text { c) Estandarización de accesorios para } \\
\text { manejo de materiales }\end{array}$ \\
\hline $\begin{array}{l}\text { d) Procedimiento para entrega de } \\
\text { muestras }\end{array}$ & $\begin{array}{l}\text { d) Procedimiento para uso de muestras } \\
\text { cromalin, matchprint }\end{array}$ & $\begin{array}{l}\text { d) Uso del tarimóvil } \\
\text { e) Cambio de Clamp metálico por uñas }\end{array}$ \\
\hline e) Procedimiento para uso de botoneras & e) Procedimiento para iluminación de & de poliuretano \\
\hline Run-Fast-Slow & centros de trabajo STPS & f) Procedimiento para recolección de \\
\hline f) Procedimiento de Identificación del & f) Procedimiento de recibo de materiales & sobrantes de opaco \\
\hline producto (etiquetas) & y acuerdos cliente-proveedor & g) Procedimiento de identificación de \\
\hline g) Procedimiento para recibo de producto & g) Procedimiento para empleo de papel & materiales (rollos) \\
\hline terminado & impreso para arreglo & $\begin{array}{l}\text { h) Procedimiento para empaques de } \\
\text { papel en planta }\end{array}$ \\
\hline
\end{tabular}

\section{Innovación prospectiva continua}

Actualmente en la firma se desarrolla un sistema para la administración de nuevas ideas, que surgen de las áreas operativas y de servicios. Cabe hacer mención que los procedimientos de producción se llevan a cabo de forma rígida, sin embargo, se ponen a prueba continuamente. Por ejemplo, si un operador descubre una manera más eficaz de realizar el trabajo, la comunica a la administración y se realizan pruebas piloto que después se convierten a nuevos estándares.

\section{Análisis de resultados}

Para el diseño de la metodología los resultados son los siguientes:

De la opinión de las empresas socias de institutos gráficos se muestra en el rubro de debilidades la necesidad de una actualización tecnológica tanto en los procesos como en los productos, así como del acelerado cambio tecnológico y del empleo de productos sustitutos que amenazan a este sector. Así mismo dentro de los rubros de las fortalezas y oportunidades se hace evidente la confianza en el dominio de los procesos y la experiencia de su personal, así como del apoyo del gobierno federal y de los proveedores, además de un mercado en franco crecimiento. La información anterior orienta a este sector para organizar a la industria gráfica en estructuras más flexibles e innovadoras que respondan a las exigencias de los mercados actuales. En cuanto a la observación de las empresas socias de institutos gráficos los conceptos que prioritariamente destacan son: proceso, producción, procesos y reducción con $42.43 \%$, seguidos de los rubros: trabajo, dirección, neurálgico, concientización y equipos con $21.22 \%$ $y$ en menor medida ideas con $1.52 \%$. Lo anterior permite observar una clara orientación de estas empresas hacia el área de procesos seguida del trabajo en equipo. Por su parte, en el punto de vista de las empresas socias de institutos gráficos, los rubros que sobresalen son equipos, trabajo y organización contabilizan con $18.81 \%$, seguidos de los conceptos de procesos e impresión con $16.83 \%$, a su vez tecnología, tecnologías, y modernización suman $13.86 \%$, finalmente las ideas, innovando e innovar con $3.96 \%$. Los resultados indican una clara inclinación hacia el trabajo en equipo, el mejoramiento de los procesos de impresión, el uso de tecnologías de vanguardia y finalmente el uso de la 
innovación como motor de desarrollo en todas las áreas de la planta de estas organizaciones. En cuanto al análisis de evaluación sumaria, los resultados determinaron que las variables de mayor impacto -que permitieron la modernización de estas empresas- en orden de prioridad son: eficiencia operacional con $26.39 \%$, modernización tecnológica con $25.70 \%$, liderazgo estratégico con $24.46 \%$, innovación prospectiva con $23.45 \%$.

Para la implementación de la metodología los resultados son los siguientes:

En cuanto al lead time los resultados demuestran que de acuerdo al comparativo 2010 Vs 2011 el tiempo de ciclo se ha visto reducido en $67.60 \%$, al pasar de 7.1 días en promedio a 2.3 días por orden. Esta reducción ha permitido incrementar la manufactura en un $22.44 \%$. Por su parte, en el Waste los indicadores demuestran una reducción drástica de $79.71 \%$ por el desperdicio de papel en planta, al pasar de 141 Tm (21.2\%) en 2010 hasta alcanzar $56 \mathrm{Tm}(4.3 \%)$ para 2011. Lo que representa un ahorro de $85 \mathrm{Tm}$ en promedio. Los retrabajos -Re Workse han vistos disminuidos en $90.19 \%$ al pasar de $5.1 \%$ en 2010 para obtener $0.5 \%$ del global en planta. Esto representa un promedio de 1.8 ordenes retrabajadas en 2011 por día, contra 15 ordenes de 2010 por día. Paralelamente el make ready ha pasado de 1.1 de día en 2010 contra un 0.02 de día para 2011, permitiendo una reducción promedio de $90.19 \%$. Finalmente el transport registra recorridos más cortos que hoy en día promedian los 20 metros, contra el layout de la manufactura clásica de la planta de 200 metros. Lo que representa una reducción de $90 \%$.

\section{Conclusiones}

La industria gráfica nacional está compuesta en $99 \%$ -18823 establecimientos- por micros, pequeñas y medianas empresas que dan empleo a unos 130434 trabajadores, cuyo porcentaje de contribución al PIB representan 2.95\%, teniendo el Distrito Federal y el Estado de México una participación de $58.9 \%$ del global nacional. Actualmente las tecnologías de impresión más importantes son: el offset litográfico, la flexografía y el huecograbado, sin embargo, la impresión digital se desarrolla rápidamente. La industria nacional de la impresión presenta las características de la necesidad de una verdadera innovación tecnológica de productos y procesos, la creación de nuevos modelos de negocios, una capacitación y organización para las tecnologías digitales, la flexibilización de materiales y procesos, el mejoramiento de la productividad, la búsqueda de estrategias de innovación tecnológica, la necesidad de mecanismos de financiamiento, el acceso a mercados globalizados. En función de las herramientas de entrevistas abiertas, observación directa y de evaluación sumaria tipo Likert, se determinaron cuatro variables que detonaron el incremento de la productividad de la planta litográfica. Estas variables son: modernización tecnológica, innovación prospectiva, eficiencia operacional y liderazgo estratégico. Paralelamente se determinó que para alcanzar la modernización tecnológica se hace necesario primeramente poner un énfasis en la eficiencia de las operaciones, el liderazgo participativo y la generación de ideas. De acuerdo a la información cualitativa y cuantitativa se conformó una metodología de doce pasos sistemáticos a través de los cuales se buscó la excelencia operativa de los procesos de manufactura que culminarían con la modernización tecnológica. Estas doce etapas pueden sintetizarse en seis etapas clave: formación de los grupos de trabajo, revisión física de la planta, medición de los indicadores de productividad, solución de las barreras de proceso, estandarización de las soluciones y la administración para las nuevas ideas. La implementación de la metodología de modernización tecnológica en una empresa litográfica es el resultado del trabajo de intervención de un grupo de cambio que inicialmente se enfocó en la eficiencia operacional y que culminó con la modernización de los procesos de manufactura. De acuerdo con las experiencias de campo y de la implementación de las herramientas basadas en manufactura integrada por computadora se concluye totalmente que para alcanzar la modernización tecnológica de la planta, se hace necesaria la simplificación de las operaciones, y esto es poner el énfasis en el mejoramiento de la productividad. Otro de los elementos transformacionales de este caso de éxito, es sin duda alguna la intervención de un fuerte liderazgo estratégico y participativo que motivó a muchos de los actores en planta a cultivar una filosofía de la innovación que permitió poner en práctica múltiples soluciones al proceso que se destacan en este trabajo de investigación, tal es el caso de las células de trabajo custom y value. 


\section{Anexo " $A$ " Guía general de observación}

Se trata de una investigación cualitativa para identificar los determinantes más significativos de la modernización tecnológica.

\begin{tabular}{|l|}
\hline Observador: \\
Lugar: \\
Fecha: \\
1.- Tema I \\
2.- Tema II \\
3.- Tema III \\
4.- Tema IV \\
5.- Tema V \\
\hline
\end{tabular}

\section{Anexo "B" Guía de entrevista}

Se trata de una entrevista tipo cualitativa y abierta, aplicada a personal administrativo y operativo.

Fecha:
Entrevistado:
Puesto:
1.- ¿Cómo ve usted la modernización que vive la industria gráfica-litográfica?
2.- ¿Qué opinión le merece la tecnología de impresión digitalizada?
3.- ¿Qué opina usted de los cambios -en materia de modernización- que
ha experimentado la planta en los últimos años?
4.- ¿Podría usted ejemplificar un caso de éxito y fracaso -muy en particular
de su área de trabajo- en el proceso de modernización que vive la planta?
5.- ¿Qué clase de herramientas de modernización le han facilitado
su trabajo?
6.- ¿Cuál fue su participación en el proceso de modernización de la planta?
7.- ¿Podría usted mencionar las ventajas de la modernización de la planta?
8.- ¿Podría usted mencionar las desventajas de la modernización de
la planta?
9.- ¿Qué semejanzas y diferencias encuentra en la planta de hoy respecto
de la anterior?
10.- ¿En su opinión general ha mejorado su productividad?

\section{Anexo "C" Cuestionario de evaluación sumaria}

Se trata de la aplicación de un cuestionario de evaluación sumaria que fue aplicado a personal administrativo y operativo.

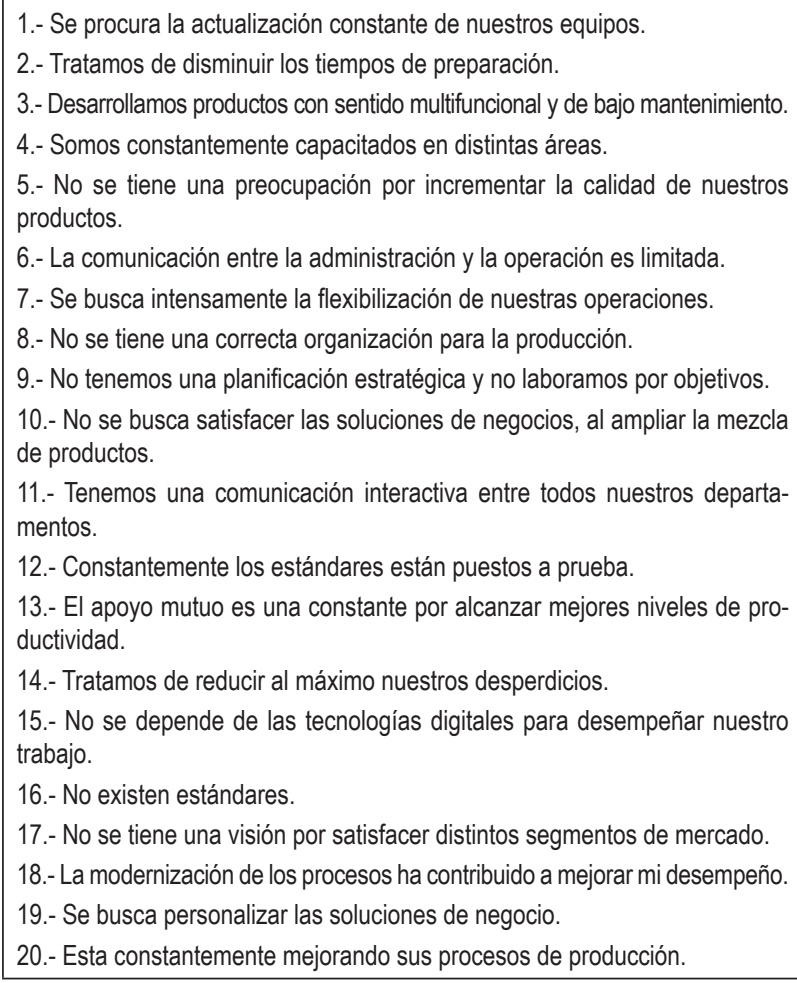

21.- La calidad de nuestros productos y procesos es preponderante.

22.- Existe un buen clima laboral entre la parte humana y la tecnología.

23.- La automatización de los procesos nos permite desempeñar mejor nuestra labor.

24.- No contamos con mecanismos que nos faciliten la evidencia de nuestros errores.

25.- Incrementamos constantemente las corridas de producción.

26.- Se respeta al pie de la letra la planificación de la producción.

27.- No nos preocupamos por el mantenimiento de la planta.

28.- No existen mecanismos para ingresar órdenes limpias y libres de aclaraciones.

29.- No se tiene una verdadera carrera profesional.

30.- Existe una preocupación constante por incrementar la investigación y el desarrollo.

31.- Se tiene un alto índice de subcontratación.

32.- Se simplifican constantemente las operaciones y se eliminan los desperdicios.

33.- No se tiene una buena codificación de materiales y productos.

34.- La dirección posee una buena estrategia de negocios.

35.- Se promueve un ambiente de competencia y de trabajo en equipo.

36.- Existen un alto índice de retrabajos y reportes de queja.

37.- Existe un auténtico liderazgo de grupo.

38.- Son altas las corridas de producción de altos volúmenes.

39.- No existe un verdadero compromiso por mejorar los procesos.

40.- No se requiere de un alto índice de supervisión. 


\section{Anexo " $\mathrm{D}$ " Cálculo del Alfa de Cronbach}

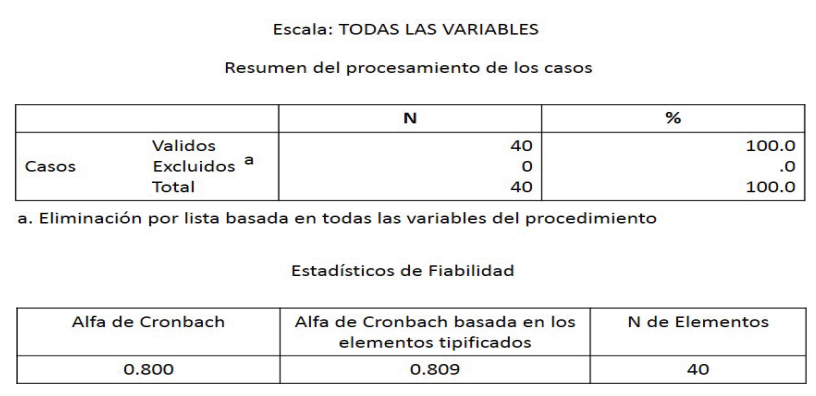

\section{Referencias}

Ántropos. Ltda. Glosario general de artes gráficas, 1a ed., Madrid, Antropos, 2010. pp. 12-13.

Arellano R.M. Actores y fines de las estrategias empresariales: Una reflexión desde las pequeñas y medianas empresas. $V i-$ sión gerencial, volumen 1 (número 1), enero-junio, 2004: 28-39.

CANAGRAF. Reporte Técnico. Estudio estratégico y programa sectorial para elevar la competitividad y el desarrollo sustentable de la cadena productiva de la industria de las artes gráficas, México, Cámara Nacional de la Industria de las Artes Gráficas, 2010, 547 p.

De la Garza E. Estrategias de modernización empresarial en México, flexibilidad y control sobre el proceso del trabajo, $1^{\underline{a}}$ ed., México, Rayuela, 1998. pp. 1-86.

De la Hoz A.I. La competitividad basada en la modernización tecnológica e informática de las industrias de pastas alimenticias del estado Zulia. SINNCO, volumen 1 (número 1), enero-junio 2010: 1-33.

Dombois R. y Pries L. Modernización empresarial. Tendencias en América Latina y Europa. Nueva Sociedad Colombia, volumen 1 (número 19), enero-junio, 1993: 157-158.

EAIM-INEGI. Reporte Técnico. Sistema de cuentas nacionales de México, México, Instituto Nacional de Estadística e Informática, 2012, 320 p.
Expo Gráfica 2009, Guadalajara Jalisco México. Competitividad: El reto a vencer en el México moderno. Reporte Técnico, Guadalajara, Jalisco, México, ANIDIGRAF, 2009, pp. 1-2.

Gamboa C.T. Estrategias de modernización empresarial. Procesos, productos y fuerza de trabajo. Revista Venezolana de Gerencia, volumen 8 (número 24), octubre-diciembre, 2003: 592-606.

Hernández R.M. Estrategias de modernización y cultura en empresas manufactureras y de servicios de las regiones norte, centro y centro occidente, UAM, 2009, 16 p.

Laffitte A. La vinculación tecnológica en instituciones de I+D, UNER, 2001, 7 p.

Manyika M.J., Roberts P.R., Sprague L.K. Eight business technology trends to watch. McKinsey $\mathcal{E}$ Co., volumen 1 (número 1), diciembre 2007: 1-10.

PRIMIR. Reporte Técnico. Global print market. Global print. Reston, Virginia USA, 2009, $20 \mathrm{p}$.

Reyes G.B. Reporte Técnico. Arquitectura de negocios, Puebla, México, Instituto Tecnológico y de Estudios Superiores de Monterrey, 2010, $31 \mathrm{p}$.

Terni C.H. Reporte Técnico. Tendencias de mercado, comercio internacional y tecnologías gráficas para los próximos años, Buenos Aires Argentina, CONLATINGRAF, 2008, 65 p.

UIA. Reporte Técnico. Debilidades y desafíos tecnológicos del sector productivo, Unión Industrial Argentina, Ciudad Autónoma de Buenos Aires, Unión Industrial Argentina, 2011, 29 p.

\section{Este artículo se cita: \\ Citación estilo Chicago}

Munive-Rojas, Miguel Ángel. Detonadores de la modernización tecnológica en la industria gráfica de México: una metodología y un caso de éxito. Ingeniería Investigación y Tecnología, XVI, 03 (2015): 317-334.

\section{Citación estilo ISO 690}

Munive-Rojas M.A. Detonadores de la modernización tecnológica en la industria gráfica de México: una metodología y un caso de éxito. Ingeniería Investigación y Tecnología, volumen XVI (número 3), julio-septiembre 2015: 317-334.

\section{Semblanza del autor}

Miguel Ángel Munive-Rojas. Doctor en planeación estratégica y gestión tecnológica por la Universidad Popular Autónoma de Puebla (UPAEP). Maestro en ciencias en ingeniería industrial con espscialización en manufactura avanzada por la sección de estudios de posgrado de la Unidad Profesional Interdisciplinaria de Ingeniería, Ciencias Sociales y Administrativas (IPN). Ingeniero industrial especializado en procesos, automatización y robótica UPIICSA-IPN. Actualmente es profesor investigador en la Facultad de Ciencias Básicas, Ingeniería y Tecnología, Campus Apizaquito de la Universidad Autónoma de Tlaxcala (UAT), pertenece al Cuerpo Académico de Diseño y Administración en Ingeniería Mecánica SEP-PRODEP. 